\title{
An Irish perspective on patients who lack the capacity to consent to treatment
}

\author{
John Hillery, David Tomkin and Adam McAuley
}

\begin{abstract}
Health care professionals in Ireland are concerned about the effect of $L$ v. Bournewood Community and Mental Health Trust, ex parte $L$ (1998). Despite Ireland's distinct legal system and different service provision, this case has highlighted existing concerns about the treatment of patients with a dual diagnosis of learning disability and mental illness.
\end{abstract}

\section{Detention and treatment of those with both learning disability and mental illness}

Historically, many people with learning disability in Ireland resided in psychiatric hospitals (Robins, 1986). Pressure from advocacy groups led to government policy stating that this should not happen in the future (Irish Department of Health, 1984). The current practice is that patients with both learning disability and mental illness may be treated and detained in their residential service (Walsh et al, 1993).

In many cases, the patients lack the capacity to consent and in Ireland are treated on a "best interests' basis. This has arisen as a consequence of parliamentary failure to deal with these issues. Both doctors and the patients' advocates are unhappy with this position.

\section{Treatment of ' $L$ ' in the Irish context}

In Ireland, people like ' $L$ ' with a learning disability would attend a day centre. They would live either with their own family or in a special residential placement.

If they were to develop the same acute agitation requiring clinical detention and intervention. it would probably occur in their residential placement or home.

Should this fail, only two treatment options remain. The first is admission to an emergency place in the generic psychiatric services. This option will require the patient to be sectioned under the Mental Treatment Acts. In Ireland, generic services do not usually treat people functioning below the mild range of learning disability. In some areas the local services have come to ad hoc arrangements in individual cases. The second option is referral to a specialist unit within the learning disability services. Only two services have residential facilities covered by the Mental Treatment Acts.

\section{The legal position in the Republic of Ireland}

In the Republic of Ireland, therapeutic detention options for those unable to consent are under the provisions of the Mental Treatment Acts, wardship or by court order. The first is not generally applicable to facilities where people with learning disability are cared for. The other two tend to be thought too cumbersome to be appropriate for clinical care of people with learning disability. Therefore, most people with learning disability requiring detention for any reason and who are unable to give consent are detained on a 'best interests' basis. The practice has arisen of obtaining proxy consent from an adult, such as a relation or a doctor in charge of the facility where the patient lives. Needless to say, this procedure, although not of itself harmful, is without legal force and does not provide sufficient protection for health professionals.

Despite misgivings about the propriety of detaining people under the Mental Treatment Acts who have behavioural problems that may not be due to an underlying mental illness, these Acts do provide those detained under them with some degree of automatic protection and safeguards such as periodic review (Tomkin \& Hanafin, 1995).

The real issues of concern to both clinicians and advocacy groups relate to persons with impaired capacity who urgently require 
treatment and/or detention and who cannot be covered properly by the provisions of the Mental Treatment Acts.

\section{Discussion}

From an Irish point of view, the House of Lords' decision in $L v$. Bournewood is particularly worrying. It represents an attempt by the House of Lords to effect a temporary compromise between the urgent requirement for forthcoming legislation and the necessity to strike a balance between the rights of patients and the protection of health care professionals and others involved in patient care. It seems to be guided more by worries about resources than by the requirement to provide a comprehensive solution to the needs of people with a specific learning disability.

The likely effect of $L v$. Bournewood in Ireland gives rise to concern. Despite the fact that Ireland has a written Constitution, the courts might well adopt the same approach as that taken by the House of Lords. The overtly interstitial nature of the decision may be lost. particularly where either Parliament fails to introduce the promised legislation or a judgement originally designed as a temporary expedient becomes the keystone of a fortuitously constructed edifice.

A new Mental Treatment Act has been promised (Irish Department of Health, 1994) and the White Paper (Irish Department of Health, 1996). which presages this legislation, outlines ways in which people with a learning disability may be covered by the new Act. Among the conditions covered by the definition of mental disorder in the White Paper is "significant mental handicap". The latter refers to "people with mental handicap with abnormally aggressive behaviour who constitute a danger to themselves or others". It is intended that certain facilities will be defined as approved centres for the purposes of involuntary admission of mentally disordered patients'. The White Paper also states that "Persons who have a significant mental handicap... will be detained in centres specialising in the care of persons with a mental handicap... Persons with a significant mental handicap whose need for involuntary admission arises from a mental illness may also be treated in approved psychiatric hospitals or units". An Adult Care Order is also proposed. This "could be used to protect mentally disordered patients who are being abused, neglected or exploited". For the purpose of the Adult Care Order, the conditions definable as mental disorder will include mental handicap, which is defined as "a state of arrested or incomplete development of mind that includes impairment of intelligence and social functioning".

The White Paper causes concern about the further stigmatisation of people with learning disability if the Mental Treatment Acts govern the main way in which they will be 'protected' when they are unable to make decisions for themselves. There are also worries about the resource implications and a perceived vagueness in some of the terminology used.

The new Mental Health Act may answer the needs of a person presenting in the same way as ' $L$ '. There remains a need to protect legally the rights of those who do not have a significant behavioural disorder but who do need to be detained. Such need can be either temporary, for anyone requiring non-psychiatric medical treatment, or permanent, as in the case of someone who may be unaware of danger and needs to be detained for his or her own safety. Protection of rights could be afforded by the legislative establishment of a system of measures involving independent third-party inspection and oversight. One particular aspect of such a review system ought to be the obligatory detailing and reassessment of deprivation of liberty, in order to ensure that, in all cases, the exclusive motive for detention is the protection of the patient's best interests. Alongside the development of such a proper protective framework must be the development of resources sufficient not only to implement such a system but also to deliver within this system the day-to-day clinical and support services. It would indeed be a tragedy if one were provided at the expense of the other.

We fully recognise the legitimacy of the concerns of administrators and health care professionals about the resulting resource implications. Nevertheless, it is imperative to provide a system of review of facilities where people with a learning disability live and are often detained in the legal sense. Most of these people do not have a significant behavioural disorder or a psychiatric illness. Advocacy groups have requested specific legislation for the care and protection of people with learning disability who are incompetent to give legal consent (Commission on the Status of People with Disabilities, 1997). What is needed is not only a general revision of the Mental Treatment Acts, but also legislation designed specifically to deal with the care of persons with a learning disability who lack consensual capacity.

\section{References}

Commission on the Status of People with Disabilmties (1997) A Strategy for Equality. Dublin: Irish Government Publications Office. 
IRISH DEPARTMENT OF HEALTH (1984) The Psychiatric Services: Planning for the Future. Dublin: Irish Government Publications Office.

- (1994) Shaping a Healthier Future: a Strategy for Effective Health Care in the 1990s. Dublin: Irish Government Publications Office.

- (1996) White Paper on Mental Health. Dublin: Irish Government Publications Office.

RoBiNS, J. (1986) Fools and Mad; a History of the Insane in Ireland. Dublin: IPA.

Tomkin, D. \& Hanafin, P. (1995) Irish Medical Law. Dublin: The Round Hall Press.

Walsh, D.. O'Kely, M., Ramsey, R., et al (1993) The relationship between behaviour disturbance and psychiatric diagnosis in male mentally handicapped adults resident in a longstay unit. Irish Journal of Psychological Medicine, 10, 16-19.
L. v. Boumewood Community and Mental Health Trust, ex parte L (1998) 3 All ER. 289.

*John Hillery, Consultant Psychiatrist, Stewart's Hospital, Dublin 20 and Associate Director, University College Dublin Centre for the Study of Developmental Disabilities, Roebuck, Belfield, Dublin 4, Ireland; and David Tomkin, Lecturer in Law, and Adam McAuley, Lecturer in Law, Dublin City University, Dublin 9, Ireland

*Correspondence

\section{CAN: Camberwell Assessment of Need}

Mike Slade, Graham Thornicroft, Linda Loftus, Michael Phelan \& Til Wykes

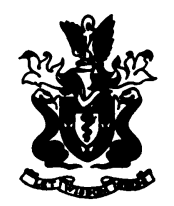

The Camberwell Assessment of Need (CAN) is a tried and tested approach to assessing the needs of the severely mentally ill which is suitable both for research studies and routine clinical use. Rigorously developed by staff at the Section of Community Psychiatry (PRiSM), Institute of Psychiatry, the CAN is suitable for use in primary care settings, specialist mental health teams, and social services. It will be of particular interest to care managers and mental health staff who wish to meet the legal requirement that the severely mentally ill receive a comprehensive needs assessment.

July 1999, £45.00, 144pp, Ringbound pack incl. photocopiable material, ISBN 1901242250

Available from Book Sales, Royal College of Psychiatrists, 17 Belgrave Square, London SW1X 8PC Tel +44 (0) 1712352351 (extension 146), Fax +44 (0) 1712451231 http://www.rcpsych.ac.uk 